\title{
Are there any relationships between personality type, salivary total antioxidant level and academic stress?
}

\author{
Hamed Mortazavi ${ }^{1, A-F}$, Mahshid Namdari ${ }^{2, C}$, Maryam Sadatrasou ${ }^{3, A, B}$, , Shervin Shafiei ${ }^{4, A, B}$, , Hamidreza Moslemi ${ }^{4, A, B},{ }^{4}$ Kosar Rezaeifar ${ }^{5, D, F}$ \\ ${ }^{1}$ Department of Oral Medicine, School of Dentistry, Shahid Beheshti University of Medical Sciences, Tehran, Iran \\ ${ }^{2}$ Department of Community Oral Health, School of Dentistry, Shahid Beheshti University of Medical Sciences, Tehran, Iran \\ ${ }^{3}$ School of Dentistry, Shahid Beheshti University of Medical Sciences, Tehran, Iran \\ ${ }^{4}$ Department of Oral and Maxillofacial Surgery, School of Dentistry, Shahid Beheshti University of Medical Sciences, Tehran, Iran \\ ${ }^{5}$ Department of Oral Medicine, School of Dentistry, Ahvaz Jundishapur University of Medical Sciences, Ahvaz, Iran \\ A - research concept and design; $\mathrm{B}$ - collection and/or assembly of data; $\mathrm{C}$ - data analysis and interpretation; \\ $D$ - writing the article; $E$ - critical revision of the article; $F$ - final approval of the article
}

Address for correspondence

Hamed Mortazavi

E-mail: hamedmortazavi2013@gmail.com

Funding sources

None declared

Conflict of interest

None declared

Received on September 4, 2020

Reviewed on December 7, 2020

Accepted on December 17, 2020

Published online on 0ctober 29, 2021

Cite as

Mortazavi H, Namdari M, Sadatrasoul M, Shafiei S, Moslemi H, Rezaeifar K. Are there any relationships between personality type, salivary total antioxidant level and academic stress? DentMed Probl. 2021;58(4):447-452. doi:10.17219/dmp/131757

DOI

$10.17219 / \mathrm{dmp} / 131757$

Copyright

○) 2021 by Wroclaw Medical University

This is an article distributed under the terms of the

Creative Commons Attribution 3.0 Unported License (CC BY 3.0)

(https://creativecommons.org/licenses/by/3.0/).

\section{Abstract}

Background. Stress is one of the most important determinants of total antioxidant capacity (TAC).

Objectives. This study aimed to assess alterations in salivary TAC following academic stress according to the personality type.

Material and methods. This descriptive study evaluated 53 dental students at Shahid Beheshti University of Medical Sciences, Tehran, Iran, who were divided into type A $(n=25)$ and type B $(n=28)$ personality groups using the Bortner questionnaire. Saliva samples were collected during the $1^{1 \text { th }}$ week of the semester (a low-stress period) and during the ${ }^{1 \text { st }}$ week of the final exams (a high-stress period). Salivary TAC was measured using a specific kit. The data was analyzed using the repeated measures analysis of variance (ANOVA), the analysis of covariance (ANCOVA), the $x^{2}$ tests, the independent $t$ tests, and the Bonferroni adjustments.

Results. Overall, salivary TAC in the high-stress period was significantly lower than that in the low-stress period $(0.27 \mathrm{vs} 0.31 \mathrm{mM})(p=0.016)$. The comparison of salivary TAC between the type $A$ and type $B$ personality groups in the low-stress period showed no significant difference $(p=0.450)$. During the highstress period, a reduction in salivary TAC was recorded in both groups, which was borderline significant in the type A personality group $(p=0.050)$, but non-significant in the type B personality group $(p=0.140)$. The comparison of salivary TAC between the type $A$ and $B$ personality groups in the high-stress period also revealed no significant difference $(p=0.780)$.

Conclusions. Academic stress can decrease salivary TAC, and the personality type has no significant effect on this relationship.

Keywords: stress, saliva, antioxidant, personality type 


\section{Introduction}

Oxidative stress is due to the impaired balance between the production of free radicals and reactive oxygen species (ROS) and antioxidant defense mechanisms. This imbalance can adversely affect various biomolecules, including lipids, proteins and nucleic acids. Oxidative stress can result from the overproduction of free radicals and ROS, or a decreased production of antioxidants. ${ }^{1-5}$ Oxidative stress can ultimately damage cells and organs, or impair their function. ${ }^{3}$ From a biomedical point of view, an antioxidant is a material that, when present at a much lower concentration as compared with that of an oxididant, can significantly prevent or delay the oxidation reaction. ${ }^{6}$

Considering the fact that the antioxidant capacity of particular antioxidants depends on the individual capability of these enzymes to counteract oxidative stress, it seems that the evaluation of each antioxidant alone would not yield conclusive results. Moreover, there are many types of antioxidants, and their individual assessment would be difficult and costly. Thus, total antioxidant capacity (TAC) is commonly measured in current research studies. ${ }^{6}$ On the other hand, the collection of saliva and urine samples is non-invasive and easier as compared to blood collection. Therefore, in recent decades, saliva and urine samples have been more commonly used than blood samples for the assessment of TAC., ${ }^{2,5}$ Moreover, it has been confirmed that a decreased salivary TAC indicates oxidative stress. In other words, the level of oxidative stress can be determined by measuring salivary TAC. ${ }^{7}$

A reduction in TAC can negatively affect general health. ${ }^{7}$ This reduction can be influenced by both physical and psychological parameters. Considering a psychological aspect, it seems that psychological stress, anxiety, depression, poor coping mechanisms, and many other psychological variables are directly related to oxidative stress, and can subsequently affect TAC. ${ }^{8,9}$ Among various stressors, academic stress refers to a type of psychological stress that can cause a predictable sense of hopelessness and academic failure, even unconsciously. ${ }^{10}$ It can be evoked by many factors associated with the academic environment. For example, academic stress in medical students can be due to exams, falling behind in studying, a lack of time to review the course material, heavy workload, the need to actively participate in classes, and requirements for good academic performance. ${ }^{11}$ Increased oxidative stress may increase psychological fatigue, and subsequently decrease learning ability. ${ }^{12}$ Ito et al. found an inverse correlation between the blood levels of reactive oxygen metabolites 3 days before national examinations and the final scores of students. ${ }^{12}$

The personality of each individual is made up of a mixture of specific characteristics. ${ }^{13}$ Considering variability in personality traits and the fact that the personality of each individual is an important predictor of their health status, it seems that stress is also related to the characteristics forming personality. Thus, in most cases, the personality type is a good predictor of the stress status. However, reports in this respect have been contradictory. ${ }^{11,13}$ In 2014, Bob et al. reported that an anxious and nervous personality was significantly positively correlated with the level of academic stress. ${ }^{11}$ According to Batti et al., as the unique patterns of feeling, thinking and behaving shape the personality of an individual, personality traits determine to a great extent the university student's ability to handle academic issues as well as their general performance. ${ }^{14}$ For example, Sakitri showed that type A personality had a positive effect on academic performance. ${ }^{15}$

The original version of the Bortner personality type questionnaire was developed in $1969 .{ }^{16}$ It contains 14 items, each consisting of 2 phrases placed at the opposite ends of a continuum ranging from an extreme type A behavior pattern (TABP) to the absence of TABP. ${ }^{16}$ Type A personality is characterized by ambition, aggressiveness, impatience, competitiveness, anxiety, and restlessness. Time is valuable to such people, and thus they are nervous and hasty. These individuals are also fearless, often intolerant, and can be workaholics due to their high energy levels. Type A individuals resist accepting their situation, and often suffer when they cannot control the situation or people around them. In contrast, individuals with type B personality are calm and present lower levels of stress. They are cool, flexible and emotional. ${ }^{13,17,18}$ According to a study by Catipović-Veselica, the levels of aggressiveness and suspicion in individuals with type A personality are higher than in the case of type B personality; however, these groups are not significantly different regarding sociability and depression. ${ }^{19}$

People living in different communities have different psychological conditions. Considering the limited number of studies on the effect of academic stress on salivary TAC and the lack of information regarding the possible influence of the personality type on alterations in salivary TAC, this study aimed to assess changes in the salivary TAC of dental students following academic stress associated with final examinations, and the role of the personality type in this respect.

\section{Material and methods}

This descriptive, cross-sectional study evaluated 53 dental students attending Shahid Beheshti University of Medical Sciences, Tehran, Iran. According to a previous study by Pani et al., ${ }^{7}$ the minimum sample size required to detect significant differences between the groups was calculated to be 24 . The alpha error and the study power were 0.05 and $80 \%$, respectively. The study protocol was approved by the ethics committee at Shahid Beheshti University of Medical Sciences (IR.SBMU. DRC.REC.1397.025). Out of the 53 students included in the study, 25 had type A and 28 had type B personality. 
The 2 groups were matched in terms of gender and age. The study population included $3^{\text {rd }}-6^{\text {th }}$ year dental students, of which $92.44 \%$ were $4^{\text {th }}$ or $5^{\text {th }}$ year dental students. The inclusion criteria for the study were as follows:

- non-alcoholics;

- the absence of malnutrition (according to the World Health Organization (WHO), malnutrition refers to deficiencies, excesses or imbalances in an individual's energy and/or nutrient intake; considering the body mass index (BMI) formula (weight in kilograms/height in meters squared), individuals with BMI $<18.5$ have malnutrition; such individuals were excluded from the study);

- no pregnancy;

- good general health and the absence of systemic diseases that are known to affect salivary TAC;

- the absence of oral mucosa lesions at the time of sampling; and

- willingness to participate in the study.

Therefore, individuals with a history of alcohol consumption, malnutrition, pregnancy, systemic diseases, the presence of oral mucosa lesions at the time of sampling, and disinclination to participate were excluded from the study.

According to various studies, the $1^{\text {st }}$ week of the semester is considered the period of the lowest academic stress, while the $1^{\text {st }}$ week of final exams is considered the period of the highest academic stress. ${ }^{7,20,21}$ In the $1^{\text {st }}$ week of the $1^{\text {st }}$ semester of the academic year 2018/2019, the questions concerning demographic data and the Bortner questionnaire (self-assessment of the personality type) were administered to $3^{\text {rd }}-6^{\text {th }}$ year dental students. A total of 60 students participated in the initial phase of the study, of which 30 had type A and 30 had type B personality. Also, saliva samples were collected from the participants at this time, and then again during the $1^{\text {st }}$ week of final exams. Overall, 25 students with type A and 28 students with type $B$ personality showed up for the $2^{\text {nd }}$ round of saliva sampling. The remaining 7 participants were excluded from the study due to poor cooperation.

\section{Saliva collection}

Unstimulated saliva samples were collected as described by Navazesh and Kumar. ${ }^{22}$ Saliva samples were collected in a resting seated position between 9 a.m. and 12 p.m. The participants were requested to refrain from eating, drinking and cigarette smoking for $2 \mathrm{~h}$ prior to saliva collection. They were requested to rinse their mouth with tap water, wait for $2 \mathrm{~min}$ for saliva to collect in their mouth, and then spit repeatedly into a test tube until $5 \mathrm{~mL}$ of saliva was collected. The collected samples were then immediately placed on ice and sent to a laboratory. The samples were centrifuged at $4^{\circ} \mathrm{C}$ for $10 \mathrm{~min}$ to remove debris, and then the saliva was frozen at $-80^{\circ} \mathrm{C}$ for later testing. ${ }^{22,23}$

\section{Measurement of salivary TAC}

Salivary TAC was measured using a TAC assay kit (96 test; ZellBio, Lonsee, Germany). This kit measures TAC via a comparison with the activity of ascorbic acid as the standard. Its mechanism of action is based on redox colorimetry in a diagnostic range of $0.125-2 \mathrm{mM}$ $(\mathrm{M}=\mathrm{mol} / \mathrm{L})$. This kit can measure TAC with an accuracy of $0.1 \mathrm{mM} .^{23}$

\section{Bortner questionnaire}

The personality type of dental students was determined using the Bortner questionnaire. This questionnaire evaluates type $\mathrm{A}$ and type $\mathrm{B}$ personality. The Bortner ordinal scale includes 14 items. Each item is composed of 2 clauses that are at the 2 ends of an 11-point Likert scale. The score obtained by each individual may range from 0 to 140 . A score of 70 was considered as the cut-off point to separate type A and type B personality, with scores 0-70 being closer to type $B$ rather than type A personality. Individuals with lower scores have a stronger type B personality. In addition, the translated Persian version of this questionnaire has been used in many studies, and its reliability and validity have been confirmed in Iranian subjects. ${ }^{24}$

In order to have an acceptable sample size, we did not consider smoking as an exclusion criterion. Nonetheless, the possible confounding effect of this variable was controlled in the statistical analysis of the data.

\section{Statistical analysis}

The data was analyzed using the IBM SPSS Statistics for Windows software, v. 21.0 (IBM Corp., Armonk, USA). The variables were compared using the repeated measures analysis of variance (ANOVA), the analysis of covariance (ANCOVA), the $\chi^{2}$ tests, the independent $t$ tests, and the Bonferroni adjustments.

\section{Results}

The 2 groups with type A and type B personality were matched in terms of gender $(p=0.770)$. In the type A personality group, 16 (64.0\%) were females and 9 (36.0\%) were males, while in the type B personality group, $19(67.9 \%)$ were females and $9(32.1 \%)$ were males. The mean age of the participants was $22.91 \pm 1.33$ years, and the 2 groups were also matched in this respect $(p=0.590)$. The mean age of the participants in the type $A$ and type B personality groups was $22.80 \pm 1.15$ years and $23.00 \pm 1.49$ years, respectively.

There were 7 smokers in this study (4 in the type A personality group and 3 in the type $B$ personality group). ANCOVA showed that their presence in the study had no confounding effect on the results $(p=0.910)$. 
In general, salivary TAC was decreased during the highacademic stress period as compared to the low-academic stress period $(0.27 \pm 0.10 \mathrm{mM}$ vs $0.31 \pm 0.09 \mathrm{mM}$; a reduction of $0.04 \mathrm{mM}$ ), irrespective of the personality type, and this reduction was statistically significant $(p=0.016)$.

The comparison of salivary TAC within the type A personality group between the low- and high-academic stress periods revealed that salivary TAC in the high-academic stress period decreased as compared to the low-academic stress period, and this reduction was borderline significant $(p=0.050)$ (Table 1$)$.

Table 1. Salivary total antioxidant capacity (TAC) in the participants during the low- and high-academic stress periods (comparisons within the groups)

\begin{tabular}{|c|c|c|}
\hline Group & $\begin{array}{c}\text { Salivary TAC } \\
{[\mathrm{mM}]}\end{array}$ & $\begin{array}{c}p \text {-value } \\
0.32 \pm 0.08 \\
\mathrm{~A}_{1}\end{array}$ \\
$\mathrm{~A}_{2}$ & $0.27 \pm 0.10$ & $0.050^{*}$ \\
$\mathrm{~B}_{1}$ & $0.30 \pm 0.11$ & \\
$\mathrm{~B}_{2}$ & $0.26 \pm 0.11$ & 0.140 \\
\hline
\end{tabular}

Data presented as mean \pm standard deviation $(M \pm S D)$;

$A_{1}$ - type A personality group during the low-academic stress period;

$A_{2}$ - type A personality group during the high-academic stress period;

$B_{1}$ - type $B$ personality group during the low-academic stress period;

$\mathrm{B}_{2}$ - type $\mathrm{B}$ personality group during the high-academic stress period;

* borderline significant.

Salivary TAC was not significantly different in the type A and type B personality groups during the lowacademic stress period, although it was slightly lower in the type B group $(p=0.450)$. Similarly, salivary TAC was not significantly different in the type A and type B personality groups during the high-academic stress period, although it was slightly lower in the type B group $(p=0.780)$ (Table 2$)$.

Table 2. Salivary total antioxidant capacity (TAC) in the participants during the low- and high-academic stress periods (comparisons between the groups)

\begin{tabular}{|c|c|c|}
\hline Group & $\begin{array}{c}\text { Salivary TAC } \\
{[\mathrm{mM}]}\end{array}$ & $p$-value \\
\hline $\mathrm{A}_{1}$ & $0.32 \pm 0.08$ & 0.450 \\
$\mathrm{~B}_{1}$ & $0.30 \pm 0.11$ & \\
$\mathrm{~A}_{2}$ & $0.27 \pm 0.10$ & 0.780 \\
$\mathrm{~B}_{2}$ & $0.26 \pm 0.11$ & \\
\hline
\end{tabular}

Data presented as $M \pm S D$.

The comparison of salivary TAC within the type B personality group between the low- and high-academic stress periods revealed that salivary TAC in the high-academic stress period decreased as compared to the low-academic stress period, but this reduction was non-significant $(p=0.140)$ (Table 1$)$.

ANCOVA also revealed that the salivary TAC of the participants was not affected by their personality type $(p=0.980)$.

\section{Discussion}

This study assessed changes in salivary TAC during low- and high-academic stress periods based on the personality type of dental students. The mean age of the participants was $22.91 \pm 1.33$ years. In this study, irrespective of the personality type, salivary TAC decreased in the high-academic stress period as compared to the low-academic stress period, indicating that academic stress due to exams affects salivary TAC, although it only lasts for a short period of time (the exam season). This finding is in agreement with the results of Pani et al.; these authors also showed that salivary TAC significantly decreased during academic exams. ${ }^{7}$ It should be noted that different academic fields may cause different stressful conditions. Akbari et al. reported that 52\% of dental students had abnormal levels of stress during the course of their education. ${ }^{25}$ It was also shown that academic stress had a significantly greater effect on the personal stress levels of dental students as compared to other factors. ${ }^{25}$ In contrast, Ito et al. found no significant change in the levels of oxidative stress derivatives in the blood samples taken from students 3 weeks and 3 days before exams. ${ }^{12}$ However, it should be noted that this latter study assessed blood TAC, and not salivary TAC.

In this study, salivary TAC in the type A personality group decreased in the high-academic stress period as compared to the low-academic stress period, and this reduction was borderline significant. A similar reduction was noted in the type B personality group, but it did not reach statistical significance. Considering the characteristics of individuals with type A personality, such as higher levels of anxiety and stress than in the case of type B personality, it is possible that individuals with type A personality are more affected by academic stress due to exams. However, this effect did not seem to be highly remarkable. The reason for this may be the competitive spirit of these individuals, which may neutralize their stress. Similar results were also reported by Bob et al. ${ }^{11}$ Further studies are required to better investigate this topic.

A search of the literature yielded no studies examining the correlation between the personality type and changes in TAC during academic stress periods to compare our results with. However, Moriana and Herruzo reported that individuals with type A personality experienced higher levels of anxiety. ${ }^{26}$ Also, anxiety can suppress antioxidant defense mechanisms. ${ }^{27}$ On the other hand, Wilkinson et al. found no significant correlation between the academic performance of students in exams and their flexibility, anxiety, stress, and depression. ${ }^{28}$ Chai and Low also reported that psychological stress was not affected by the personality type. ${ }^{29}$ In addition, Matos-Gomes et al. found that the concentration of total protein in participants was not significantly different between 2 groups - with and without psychological stress - during low- and high-academic stress periods. ${ }^{20}$ 
It seems that individuals may find ways to cope with life stressors in their personal life experiences. In other words, they acquire experience, expertise and skills to deal with a specific stressor. Such variations in the results across studies may be due to multiple reasons, e.g., different methodologies, different methods for the assessment of salivary TAC or individual antioxidants, the type of kits used for this purpose, the inclusion and exclusion criteria, the sample size, the use of stimulated or unstimulated saliva, the collection of urine, blood or saliva samples, geographical location, or the socioeconomic status of the participants.

According to the present results, salivary TAC during the high-academic stress period was not affected by the personality type, and only depended on salivary TAC in the low-academic stress period. In other words, individuals with a higher salivary TAC in the $1^{\text {st }}$ week of the semester also showed a higher salivary TAC during the high-academic stress period. Since the salivary TAC of the individuals in the 2 groups was not significantly different in the low-academic stress period, the difference in the high-academic stress period was still non-significant.

One strategy to decrease the level of stress in students is to change the method of assessment of their academic performance. For instance, Ali et al. found that stress levels in students whose performance in exams was reported as pass/fail were lower in comparison with students whose performance in exams was reported as a grade point average. ${ }^{30}$ This factor can also be considered as a potential confounder in previous studies.

\section{Limitations}

Finally, it is necessary to state that this study has several limitations. Firstly, only one aspect and one tool assessing the specific traits of personality were used. We did not assess the study groups in terms of personality disorders, which also could be an important confounder. In addition, using only self-assessment tools to determine personality traits may introduce bias. Therefore, it is recommended that future studies use clinical examinations, such as properly structured interviews, to assess personality in a more comprehensive way.

\section{Conclusions}

This study showed that academic stress could significantly decrease salivary TAC, and that personality type had no significant effect on this relationship.

\section{ORCID iDs}

Hamed Mortazavi (i) https://orcid.org/0000-0002-0778-5299 Mahshid Namdari (1) https://orcid.org/0000-0002-7069-6977 Maryam Sadatrasoul (1) https://orcid.org/0000-0002-9622-2809 Shervin Shafiei (1) https://orcid.org/0000-0002-0415-4678 Hamidreza Moslemi (1) https://orcid.org/0000-0001-8568-6571 Kosar Rezaeifar (10) https://orcid.org/0000-0002-9850-3364

\section{References}

1. Møller $\mathrm{P}$, Wallin $\mathrm{H}$, Knudsen LE. Oxidative stress associated with exercise, psychological stress and life-style factors. Chem Biol Interact. 1996;102(1):17-36. doi:10.1016/0009-2797(96)03729-5

2. Peluso I, Raguzzini A. Salivary and urinary total antioxidant capacity as biomarkers of oxidative stress in humans. Patholog Res Int. 2016;2016:5480267. doi:10.1155/2016/5480267

3. Sivonová M, Zitnanová I, Hlincíková L, Skodácek I, Trebatická J, Duracková Z. Oxidative stress in university students during examinations. Stress. 2004;7(3):183-188. doi:10.1080/10253890400012685

4. Srivastava R, Batra J. Oxidative stress and psychological functioning among medical students. Ind Psychiatry J. 2014;23(2):127-133. doi:10.4103/0972-6748.151684

5. Tamaki N, Yoshino F, Fukui M, et al. Relationship among salivary antioxidant activity, cytokines, and periodontitis: The Nagasaki Island study. J Clin Periodontol. 2015;42(8):711-718. doi:10.1111/jcpe.12438

6. Battino M, Ferreiro M, Gallardo I, Newman HN, Bullon P. The antioxidant capacity of saliva. J Clin Periodontol. 2002;29(3):189-194. doi:10.1034/j.1600-051x.2002.290301x.x

7. Pani SC, Al Khabbaz HJ, Bin Enayeg SH, Bin Zouman AH. The relationship between examination-related academic stress, salivary antioxidant capacity and exercise patterns of final-year Saudi dental students. Eur J Dent Educ. 2017;21(4):e83-e88. doi:10.1111/eje.12225

8. Matsushita M, Kumano-Go T, Suganuma N, et al. Anxiety, neuroticism and oxidative stress: Cross-sectional study in non-smoking college students. Psychiatry Clin Neurosci. 2010;64(4):435-441. doi:10.1111/j.1440-1819.2010.02109.x

9. Colaianna M, Schiavone S, Zotti M, et al. Neuroendocrine profile in a rat model of psychosocial stress: Relation to oxidative stress. Antioxid Redox Signal. 2013;18(12):1385-1399. doi:10.1089/ars.2012.4569

10. Lal K. Academic stress among adolescent in relation to intelligence and demographic factors. AIJRHASS. 2014;5(1):123-129. http://iasir.net/AIJRHASSpapers/AIJRHASS14-150.pdf. Accessed September 1, 2020.

11. Bob MH, Popescu CA, Pîrlog R, Buzoianu AD. Personality factors associated with academic stress in first year medical students. HVM Bioflux. 2014;6(1):40-44. http://www.hvm.bioflux.com.ro/docs/2014.40-44.pdf. Accessed September 1, 2020.

12. Ito $Y$, Nakamura $A$, Adachi $M$, et al. Blood oxidative stress levels and urinary dopamine values reflect the impact of academic stress on students. J Anal Bio-Sci. 2009;32(5):422-426.

13. Yavagal $P C$, Singla $H$. Prevalence of dental caries based on personality types of 35-44 years old residents in Davangere city. J Oral Biol Craniofac Res. 2017;7(1):32-35. doi:10.1016/j.jobcr.2016.09.004

14. Batti MN, Rasli A, Haider M, Qureshi MI. Relationship between personality traits and academic stress among postgraduate students in Pakistan. EpSBS. 2018;40:583-591. doi:10.15405/epsbs.2018.05.47

15. Sakitri G. The relationship among student stress, Type A personality, and academic performance in a business school in Indonesia. J Educ Bus. 2020;95(3):169-179. doi:10.1080/08832323.2019.1627994

16. Bortner RW. A short rating scale as a potential measure of pattern A behavior. J Chronic Dis. 1969;22(2):87-91. doi:10.1016/00219681(69)90061-7

17. Shaygannejad V, Dehnavi SR, Ashtari F, et al. Study of type A and $B$ behavior patterns in patients with multiple sclerosis in an Iranian population. Int J Prev Med. 2013;4(Suppl 2):S279-S283. PMID:23776738. PMCID:PMC3678232.

18. Catipović-Veselica K. Bortner type A scores and basic emotions: Aggression, distrustful, depression, and gregarious. Psychol Rep. 2003;93(1):132-134. doi:10.2466/pr0.2003.93.1.132

19. Catipović-Veselica K. The type A-B behavior pattern in urban and rural men and women. Psychol Rep. 2001;88(3 Pt 1):915-916. doi:10.2466/pr0.2001.88.3.915

20. Matos-Gomes N, Katsurayama M, Makimoto FH, et al. Psychological stress and its influence on salivary flow rate, total protein concentration and IgA, IgG and IgM titers. Neuroimmunomodulation. 2010;17(6):396-404. doi:10.1159/000292064

21. Knowles SR, Nelson EA, Palombo EA. Investigating the role of perceived stress on bacterial flora activity and salivary cortisol secretion: A possible mechanism underlying susceptibility to illness. Biol Psychol. 2008;77(2):132-137. doi:10.1016/j.biopsycho.2007.09.010 
22. Navazesh M, Kumar SKS. Measuring salivary flow: Challenges and opportunities. J Am Dent Assoc. 2008;139(Suppl):35S-40S. doi:10.14219/jada.archive.2008.0353

23. Bakhtiari S, Azimi S, Mehdipour M, Amini S, Elmi Z, Namazi Z. Effect of cigarette smoke on salivary total antioxidant capacity.JDent Res Dent Clin Dent Prospects. 2015;9(4):281-284. doi:10.15171/joddd.2015.049

24. Heydari $H$, Bagherian $F$, Abadi JF, et al. The effect of the environment (real and virtual) and the personality on the speed of decision making. Procedia Soc Behav Sci. 2011;15:2411-2414. doi:10.1016/j. sbspro.2011.04.118

25. Akbari M, Nejat A, Dastorani S, Rouhani A. Evaluation of stress level and related factors among students of Mashhad Dental School (Iran) in academic year of 2008-2009 [in Persian]. J Mashhad Dent. 2011;35(3):165-176. doi:10.22038/JMDS.2011.956

26. Moriana JA, Herruzo J. Type A behavior pattern as a predictor of psychiatric sick-leaves of Spanish teachers. Psychol Rep. 2005;96(1):77-82. doi:10.2466/pr0.96.1.77-82

27. Edwards JR, Baglioni AJ Jr., Cooper CL. The psychometric properties of the Bortner Type A Scale. Br J Psychol. 1990;81(Pt 3):315-333. doi:10.1111/j.2044-8295.1990.tb02364.x

28. Wilkinson TJ, McKenzie JM, Ali AN, Rudland J, Carter FA, Bell CJ. Identifying medical students at risk of underperformance from significant stressors. BMCMed Educ. 2016;16:43. doi:10.1186/s12909-016-0565-9

29. Chai MS, Low CS. Personality, coping and stress among university students. Am J Appl Psychol. 2015;4(3-1):33-38. doi:10.11648/j. ajap.s.2015040301.16

30. Ali M, Asim H, Edhi Al, et al. Does academic assessment system type affect levels of academic stress in medical students? A crosssectional study from Pakistan. Med Educ Online. 2015;20:27706. doi:10.3402/meo.v20.27706 